NBER WORKING PAPER SERIES

\title{
THE IMPACT OF ANTIHYPERTENSIVE DRUGS ON THE NUMBER AND RISK OF DEATH, STROKE AND MYOCARDIAL INFARCTION IN THE UNITED STATES
}

\author{
Genia Long \\ David Cutler \\ Ernst R. Berndt \\ Jimmy Royer \\ Andrée-Anne Fournier \\ Alicia Sasser \\ Pierre Cremieux \\ Working Paper 12096 \\ http://www.nber.org/papers/w12096
}

\author{
NATIONAL BUREAU OF ECONOMIC RESEARCH \\ 1050 Massachusetts Avenue \\ Cambridge, MA 02138 \\ March 2006
}

The authors gratefully acknowledge research support for this project received from Novartis Pharma AG, which had no role in the design of the study, the collection, analysis, and interpretation of the data, or the preparation or approval of the manuscript for publication. The views expressed herein are those of the author(s) and do not necessarily reflect the views of the National Bureau of Economic Research.

(C2006 by Genia Long, David Cutler, Ernst R. Berndt, Jimmy Royer, Andrée-Anne Fournier, Alicia Sasser, and Pierre Cremieux. All rights reserved. Short sections of text, not to exceed two paragraphs, may be quoted without explicit permission provided that full credit, including $\odot$ notice, is given to the source. 
The Impact of Antihypertensive Drugs on the Number and Risk of Death, Stroke and Myocardial Infarction in the United States

Genia Long, David Cutler, Ernst R. Berndt, Jimmy Royer, Andrée-Anne Fournier, Alicia Sasser, and Pierre Cremieux

NBER Working Paper No. 12096

March 2006

JEL No. I1, O3

\section{$\underline{\text { ABSTRACT }}$}

Estimating the value of medical innovation is a continual challenge. In this research, we quantify the impact of antihypertensive therapy on U.S. blood pressures, risk and number of heart attacks, strokes, and deaths. We also consider the potential for further improvements. We estimate the value of innovation using equations relating blood pressure to adverse outcomes from the Framingham Heart Study. Our results show that without antihypertensive therapy, 1999-2000 average blood pressure for the U.S. population age 40 plus would have been 10-13 percent higher. 86,000 excess premature deaths from cardiovascular disease (2001), and 833,000 hospital discharges for stroke and heart attacks (2002) would have occurred. Life expectancy would be 0.5 (men) and 0.4 (women) years lower. At guideline care, there would have been 89,000 fewer premature deaths (2001) and 420,000 fewer hospital discharges for stroke and heart attack (2002) than observed. Our analysis suggests that antihypertensive therapy has had a significant impact on cardiovascular health outcomes but that mortality gains would have been approximately twice as high if guideline care had been achieved for all.

\begin{tabular}{|c|c|c|}
\hline Genia Long & Ernst Berndt & Andrée-Anne Fournier \\
\hline Analysis Group, Inc. & Massachusetts Institute of & Groupe d'analyse \\
\hline 111 Huntington Avenue, $10^{\text {th }}$ & Technology & 1080, Coté du Beaver Hall \\
\hline Floor & Department of Economics & Bureau 1810 \\
\hline Boston, MA 02199 & Sloan School of Management & Montréal (Québec) H2Z 1S8 \\
\hline glong@analysisgroup.com & 50 Memorial Drive, E52-452 & Canada \\
\hline David Cutler & $\begin{array}{l}\text { Cambridge, MA } 02142 \\
\text { and NBER }\end{array}$ & afournier@analysisgroup.com \\
\hline \multicolumn{2}{|c|}{$\begin{array}{l}\text { Harvard University, Department erberndt@mit.edu } \\
\text { of Economics }\end{array}$} & $\begin{array}{l}\text { Alicia Sasser } \\
\text { Federal Reserve Bank of Boston }\end{array}$ \\
\hline Littauer Center & Jimmy Royer & P.O. Box 55882 \\
\hline 1875 Cambridge Street & Groupe d'analyse & Boston, MA 02205 \\
\hline $\begin{array}{l}\text { Cambridge, MA } 02138 \\
\text { and NBER }\end{array}$ & $\begin{array}{l}\text { 1080, Coté du Beaver Hall } \\
\text { Bureau } 1810\end{array}$ & alicia.sasser@bos.frb.org \\
\hline \multirow[t]{4}{*}{ dcutler@harvard.edu } & Montréal (Québec) H2Z 1S8 & Pierre Cremieux \\
\hline & Canada & Analysis Group, Inc. \\
\hline & jroyer@analysisgroup.com & $\begin{array}{l}111 \text { Huntington Avenue, } 10^{\text {th }} \\
\text { floor }\end{array}$ \\
\hline & & $\begin{array}{l}\text { Boston, MA } 02199 \\
\text { pcremieux@analysisgroup.com }\end{array}$ \\
\hline
\end{tabular}


Hypertension is an established risk factor for conditions including coronary heart disease (CHD), myocardial infarction (MI), and stroke. Over 50 million adults were hypertensive in 1999-2000, including 43 percent of adults age 40 and over (i.e., had Stage I or II blood pressures, or reported taking antihypertensive medicine). The risk of developing hypertension increases with age; lifetime risk is estimated at approximately 90 percent for individuals with normal blood pressures at age 55 or 65 and who survive to age 80 to 85.1 The economic burden of CHD and stroke is substantial. Applying the methodologies of Rice et al. and Hodgson and Cohen to 2002 data, the total economic burden of CHD and stroke is estimated at \$120.6 and \$48.9 billion, respectively.2,3

Drug therapy for hypertension has improved over the past four decades. Only limited drug therapy existed in the late 1950s and early 1960s; the only FDA-approved drug therapies for hypertension were vasodilators (approved in 1946), peripherally acting agents (1953) and diuretics (1958). ${ }^{4}$ Most patients who would be treated immediately today with effective drug therapy were untreated, or treated less effectively. For example, while Harrison's Principles of Internal Medicine (1962) found that diastolic blood pressure was important in determining mortality, it justified treatment only in properly selected cases, stating, "A woman who has tolerated her diastolic pressure of 120 for 10 years without symptoms or deterioration does not need specific treatment for hypertension." ${ }^{, 5}$ As late as 1971-75, only nine percent of the population age 40 and over with hypertension reported in NHANES taking medication for it, and blood pressures were poorly controlled; 79 percent of this treated group still had Stage I or II blood pressures. Thus, the earlier time period could be called "drug-naïve" with regard to widespread use of a range of effective drug therapies. 
Over time, additional antihypertensive drugs became available - calcium channel blockers and beta blockers (1970s and 1980s), and ACE inhibitors and angiotensin receptor antagonists (1980s and 1990s). In 1999-2000, we calculate that 61 percent of the population age 40 and over with hypertension reported in NHANES taking medication.

Our objective is to estimate the actual impact of antihypertensive therapy on the U.S. population over the past four decades and identify potential further improvements if guideline care were achieved. Despite documented major strides in cardiovascular disease management, there has been no systematic estimate of the total impact of antihypertensive therapy on health outcomes. We use national survey data to estimate the impact of drug treatment on average blood pressures, and the best-available published risk equations to estimate the impact on the risk and number of MI, strokes, and deaths. Because the objective is to estimate the "real world" impact of antihypertensive therapy on outcomes for the entire population, representative national survey data were used, rather than estimates derived from highly controlled clinical trials. 


\section{METHODS}

\section{Data Sources}

We use data on 5,046 individuals age 30-79 from the 1959-62 National Health

Examination Survey (NHES) and 2,284 individuals age 40-79 from the 1999-2000

National Health and Nutrition Examination Survey (NHANES); U.S. life expectancy

tables from the National Center for Health Statistics (NCHS); hospital discharge figures

from the National Hospital Discharge Survey (NHDS); and published risk equations from the Framingham Heart Study. All observations from NHES and NHANES populated with the required data were included in calculations, which were performed using SAS, release 9.1 .

\section{Statistical Analysis}

Determinants of hypertension, including body mass index (BMI), diabetes, family history, excessive alcohol use, high salt diet, exercise, race, age and sex were identified from literature searches. Data on BMI, diabetes, race, age and sex were used to model observed blood pressure among a drug-naïve sample (the 1959-62 NHES sample).

The relationship between blood pressure (BP) and these explanatory factors was estimated using ordinary least squares (OLS) regression, with separate equations for systolic and diastolic blood pressure, and for men and women. 
The explanatory variables are race (BLACK, OTHER, with white being the omitted category), AGE (nine variables corresponding to five-year cohorts beginning with age 35, age 30-34 being the omitted category), $\mathrm{BMI} \mathrm{BMI}^{2}$ (to account for possible nonlinearities in the effect of BMI on BP), and DIABETES (either reporting taking insulin or having a blood glucose level $>140 \mathrm{mg} / \mathrm{dL}$ ) DIABETES, BMI, and $\mathrm{BMI}^{2}$ terms control for the impact of secular population changes in the levels of diabetes and obesity.

To predict BP in the absence of antihypertensive drug therapy, the estimated structural relationship based on data from 1959-62 is applied to observed values of the explanatory variables for individuals in the 1999-2000 NHANES sample. Following JNC-V definitions, predicted and observed systolic (SBP) and diastolic (DBP) BPs for each individual are assigned to five categories: Optimal, Normal, High Normal, Stage I and Stage II Hypertension. ${ }^{6}$ The resulting distribution of predicted BPs for 1999-2000 is compared to the distribution of observed BPs. Controlling for other identified risk factors for which data are available, the difference between the two distributions is attributed to antihypertensive therapy. Two risk factors - sodium intake and exercise - could not be included in the predictive model because data are available only for 1999-2000. A sensitivity analysis of the impact of these variables on BP, using 1999-2000 data, was conducted.

The impact of antihypertensive therapy on risk of death and total deaths from CHD is estimated using Framingham Heart Study risk equations estimated by Wilson et $a l^{7}$, together with NCHS population life tables and cause of death statistics. The impact of antihypertensive therapy on risk of stroke and MI, and hospital discharges for stroke 
and MI is estimated using Framingham Heart Study risk equations estimated by Anderson et $_{\mathrm{al} .}{ }^{8}$, and NHDS hospital discharge statistics.

The Wilson et al. risk equations are generated from a hazard model predicting the probability of a CHD event (angina, MI, or death from CHD) within the next 10 years, and include variables for age, total cholesterol, HDL-C, BP, diabetes and smoking. These equations are applied to each individual in the NHANES sample based on the individual's observed characteristics. For each individual, the probability of a CHD event within 10 years is calculated based on (1) observed BP and (2) predicted BP in the absence of antihypertensive therapy, and a relative risk ratio calculated by dividing the two. The calculated relative risks are averaged across individuals within each sex-age cohort, according to sample population weights. Since the variable of interest is death from major cardiovascular disease, average risks are combined with the probabilities for men and women of a given age, n, surviving to age $n+1$ (from the NCHS life tables), ${ }^{9}$ and with the share of deaths due to major cardiovascular disease (ICD/10 I00-I78) by sex-age cohort (from NCHS cause of death tables by sex and age). ${ }^{10}$ By adjusting for the share of total mortality due to death from major cardiovascular disease, increases in the risk of a CHD event in the next 10 years are assumed to increase the risk of death from major cardiovascular disease in the next 10 years proportionally. Improvement in life expectancy attributable to antihypertensive therapy is calculated as the difference between life expectancy at birth reported by NCHS (with observed BPs) and calculated with predicted BPs. Predicted life expectancy is derived by adjusting the risk of death in each year for men and women age 40 and above by the relative risk described for the corresponding sex-age cohort, and summing over all ages. 
The Anderson et al. risk equations are generated from separate parametric models predicting the probability of stroke and MI for men and women of given characteristics (age, BP, smoking, ratio of total cholesterol to HDL-C, diabetes and ECG-LVH) over the next 4 to 12 years. The recommended specification incorporating SBP is used. For each individual, the risk of stroke and $\mathrm{MI}$, respectively, in the next five years is calculated based on (1) observed BP and (2) predicted BP in the absence of antihypertensive therapy, and a relative risk ratio calculated by dividing the two. The number of avoided hospital discharges is calculated by applying the relative risk ratio to hospital discharge statistics for stroke (ICD/9 430-438) and MI (ICD/9 410) by sex and age from the NHDS for 2002. These risk equations allow us to isolate the effect of BP from other factors such as secular changes in serum cholesterol levels, diabetes rates and smoking, which also affect CHD risk. 


\section{RESULTS}

\section{Predictive Structural Model of Untreated Blood Pressure}

OLS multivariate regression relating SBP and DBP to risk factors was used with a sample of 2,382 men and 2,664 women age 30-79 from the 1959-62 NHES. Results appear in Table 1.

\section{Table 1}

Figure 1 is derived by applying the structural relationship from the untreated BP model for men and women, respectively, to observed characteristics of individuals in the 1999-2000 NHANES sample. The predicted SBPs and DBPs without antihypertensive drug therapy and observed BPs for each individual are assigned to five categories: Optimal, Normal, High Normal, Stage I and Stage II Hypertension. If an individual's predicted systolic and diastolic BPs are in different categories, the more hypertensive category is assigned.

\section{Figure 1}

For example, observed BPs for men age 40-49, treated or not, were: 36 percent Optimal, 26 percent Normal, 21 percent High Normal, 14 percent Stage I and 3 percent Stage II Hypertensive. For the same cohort, predicted BPs without treatment were: 22 
percent Optimal, 22 percent Normal, 19 percent High Normal, 27 percent Stage I and 10 percent Stage II Hypertensive.

Calculating weighted average BPs for each sample, we find that in the absence of antihypertensive drug therapy, average BPs for the population over 40 would be 10-13 percent higher (10.0 to 10.7 percent for men and 10.4 to 12.9 percent for women for SBP and DBP, respectively). Women age 70-79 exhibited the greatest difference between predicted and observed BPs, with 61 percent predicted and 29 percent observed with Stage II hypertension, compared to 41 and 12 percent, respectively, for men age 70-79. However, these women also experienced rates of Stage II hypertension 2.5 times higher than their male counterparts.

\section{Statistical Sensitivity Analyses}

To allow for nonlinearities, the continuous BMI variables in the BP prediction equation were replaced by six categories from the literature: "less than or within normal BMI range", "marginally overweight", "overweight", "very overweight”, "severely obese”,

and "morbidly/super obese". ${ }^{11}$ The relationship between BP and BMI is linear for women and weakly concave for men.

Variables measuring reported sodium intake and exercise habits (available only for 1999-2000) were also included in the model. Both have been identified as hypertension risk factors in the literature. Neither increased the explanatory power of the model significantly; the predicted BP distributions were nearly identical with or without these variables. Variables for sodium intake were never statistically significant and often 
had incorrect signs, while the exercise variable was occasionally significant. They had no significant impact on $\mathrm{BMI}$ or $\mathrm{BMI}^{2}$ coefficients, and increased the $\mathrm{R}^{2}$ measure only at the third decimal point. To assess possible non-normality in the model's error terms, a log-transformation of the dependent variable was regressed on the same variables. This specification did not increase the model's explanatory power nor the precision of the estimated coefficients significantly.

\section{Impact of Blood Pressure on Life Expectancy and Total Deaths from Major Cardiovascular Disease}

Applying the Wilson et al. risk equation for CHD events within the next 10 years to each individual in the 1999-2000 sample, and averaging the effect over the entire population, the total increase in life expectancy associated with antihypertensive drug therapy is 0.5 years (men) 0.4 years (women). Averaged over only the population with predicted Stage I or Stage II hypertension, the values are 0.9 years (men) and 0.6 years (women). Applying the change in risk of death to total deaths for each sex-age cohort, an estimated 86,000 excess premature deaths from cardiovascular disease (50,000 men, 36,000 women) would have occurred in 2001 among the U.S. population age 40 plus in the absence of antihypertensive drug therapy. For adults age 40 plus, observed 2001 total deaths and deaths from major cardiovascular disease are four and nine percent lower, respectively, than predicted levels with untreated BPs. Due to potential competitive mortality, these estimates represent reductions in premature deaths due to cardiovascular disease; reductions in total mortality from all causes in a given year may be lower. 
If all patients with Stage I or Stage II hypertension who reported being untreated had been treated, as recommended in JNC $7^{12(\mathrm{p} 1211)}$, and all treated patients achieved normal BPs, we calculate an additional 89,000 fewer premature deaths from major cardiovascular disease in 2001 than actually occurred. This is likely an underestimate because it assumes that those dying are no more likely to have high BP than the general population.

\section{Impact of Blood Pressure on MI and Stroke}

Similarly, for each individual in the NHANES 1999-2000 sample, we calculate the separate risks of stroke or MI within the next five years, applying the Anderson et al. equations. In the absence of antihypertensive drug therapy, there would have been 572,000 more hospital discharges for stroke in 2002 (162,000 men, 410,000 women), and 261,000 more discharges for MI ( 87,000 men, 174,000 women). This is a 38 percent reduction in discharges for stroke and a 25 percent reduction for MI, compared to predictions with untreated BPs. Most of this improvement represents stroke and MI avoided altogether, rather than delayed. Even if all the predicted reduction in discharges were for patients with predicted Stage II hypertension (those most likely to have a stroke in the future), we calculate only seven percent of discharges for stroke and five percent for MI would have occurred in the future; the remainder were avoided altogether.

We also calculate considerable improvements if guideline care were achieved. If all untreated patients with Stage I or Stage II hypertension had been treated, and all treated patients achieved normal BPs, there would have been an additional 278,000 
(stroke) and 142,000 (MI) fewer hospital discharges in 2002 than actually occurred. This is likely an underestimate because it assumes that those discharged for stroke and MI are no more likely to have high BP than the general population.

\section{Table 2}




\section{DISCUSSION}

By many measures, hypertension is much better treated now than in the past. Although further efforts are still needed to bring health benefits to all, awareness, treatment, and control of hypertension have shown considerable improvement since

NHANES II (1976-80) ${ }^{12(\mathrm{p} 1207)}$. The estimated impact of antihypertensive therapy on BP is substantial: approximately 10 percent (SBP) and 13 percent (DBP) for both men and women age 40 plus, compared to predicted untreated BP. Better-controlled BP translated into nine percent fewer deaths from major cardiovascular disease in 2001, and 38 percent and 25 percent fewer hospital discharges for stroke and MI in 2002, respectively, compared to predicted levels in the absence of drug therapy. Placing the estimated reduction of approximately 86,000 deaths in context, U.S. deaths from motor vehicle accidents totaled approximately 42,000 in $2001 .^{13}$

\section{Figure 2}

This study quantifies the impact of antihypertensive drugs in terms of avoided premature deaths from cardiovascular disease and excess hospitalizations for stroke and MI. Assigning a monetary value to these outcomes and drawing on figures from the literature for 1998, we calculate a benefit-cost ratio of over 12:1 for men and 11:1 for women by comparing life expectancy benefits to antihypertensive drug expenditures. We assume each year of additional life in good health is valued at $\$ 90,000$ (a generally accepted value of $\$ 100,000$, less $\$ 10,000$ in average support costs during non-working years paid by government), ${ }^{14}$ and expenditures on antihypertensive drugs average $\$ 2,600$ 
for men (over a 73.8-year expected lifespan) and \$3,248 for women (over a 79.5-year expected lifespan). ${ }^{15}$ We discount both costs and benefits at three percent a year, the inflation-adjusted U.S. Treasury bond yield.

Previous studies have concluded that antihypertensive treatment is cost-effective; Weinstein reports estimates of the number of quality-adjusted life years achieved with each $\$ 1$ million spent on antihypertensive drug therapy as between $20-50$ (antihypertensive treatment, DBP 95-104) to more than 200 (beta-blockade postmyocardial infarction, high risk). As a benchmark, $\$ 1$ million spent for dialysis for endstage renal disease is estimated to yield 10-20 quality-adjusted life years. ${ }^{16}$

Reduced hospitalizations for stroke and MI increase calculated net benefits further. Dividing figures from the literature for total hospital costs for CHD and cerebrovascular disease ${ }^{17,18}$ by corresponding hospital discharges, and assuming hospital costs represent 70 percent of direct medical costs in the year following stroke and MI, ${ }^{19}$ we estimate 2002 total direct medical costs avoided due to fewer strokes and MI of $\$ 10.7$ billion and $\$ 5.8$ billion, respectively. Including the impact of antihypertensive drugs on quality of life and work productivity would increase the benefit-cost ratio further.

While the benefits have been substantial, significant opportunities remain to extend drug treatment to more who could benefit. We estimate life expectancy could increase an additional 0.3 years (men) and 0.1 years (women) if therapy were extended to all with Stage I or Stage II hypertension not currently treated with medication, and an additional 0.2 years for both men and women if those treated achieved normal BP. These figures translate into an additional 89,000 avoided premature deaths from major 
cardiovascular disease, and an additional 278,000 (stroke) and 142,000 (MI) avoided hospital discharges, compared with actual 2002 levels.

\section{Study Limitations}

The methodology used is a residual analysis. It controls for all risk factors for which data are available, and confirms that omitted sodium and exercise variables are unlikely to have a significant impact. There remains, however, the possibility that unknown factors may have contributed to differences between observed and predicted BPs. In particular, some researchers suggest a downward cohort effect due to unknown, population-level factors. Using the same datasets, Goff et al. find that the $10^{\text {th }}, 50^{\text {th }}$, and $90^{\text {th }}$ percentile levels of observed BP by age were lower for more recent birth cohorts. However, because observed BPs include both treated and untreated BPs, the observed cohort effect is confounded by the impact of treatment. Even in lowest-decile SBPs, where "pharmacologic management is unlikely to have had any impact,"20 1999-2000 NHANES data show nine percent age 40 plus reported taking hypertension medication (increasing to 29 percent age 60 plus). We adjust for this confounding treatment effect by calculating the ratio of untreated to all lowest-decile SBPs in the 1999-2000 sample (by age), and adjusting the authors' estimates thereby. Assuming the improvement in the lowest decile, as adjusted, to be entirely due to a cohort effect would reduce our estimate of the impact of BP improvements modestly, from a nine- to an eight-percent reduction in 2001 premature deaths from cardiovascular disease. 
Our calculations assume the 1959-62 data provide a reliable predictive basis for calculating the structural relationship between BP and explanatory variables, notably BMI and $\mathrm{BMI}^{2}$, and that the sample is "drug-naïve." While NHANES data are available for subsequent time periods (1971-75, 1976-80, 1988-94, and 1999-2000), their suitability for estimating this relationship is compromised by the increasing proportion being treated with antihypertensive drugs, thereby rendering the remaining untreated population increasingly unrepresentative. When similar equations are estimated in later years with only the remaining untreated individuals, the predicted impact of a change in $\mathrm{BMI}$ (and $\mathrm{BMI}^{2}$ ) on $\mathrm{BP}$ was always positive, but generally became smaller over time, consistent with an increasingly selective untreated population. While treatment rates were low in 1959-62 and few effective clinical options were available, to the degree that some individuals were treated effectively, predicted untreated BPs for 1999-2000, and therefore the estimated impact of treatment on mortality and morbidity, would be understated. The study design may also overestimate strokes and MI avoided due to a "survival bias"; specifically, in the absence of effective BP control, the total population with hypertension would have been smaller and some individuals who had a stroke or MI in 2002 would have died previously. However, there is a likely countervailing underestimation effect, in that those discharged for stroke and MI are assumed to be no more likely to have high BP than the general population. The net impact of these effects is unknown.

Finally, the study design relies on Framingham Heart Study risk equations. To the degree that these equations were estimated on an essentially all-white population, and that cardiovascular risk for the same level of BP may be higher for non-white 
populations, all other factors held constant, we have underestimated the impact of treatment. 


\section{REFERENCES}

1. Vasan RS, Beiser A, Seshadri S, Larson MG, Kannel WB, D'Agostino RB, et al. Residual lifetime risk for developing hypertension in middle-aged women and men: The Framingham Heart Study. JAMA. 2002; 287: 1003-1010.

2. Rice DP, Hodgson TA, Kopstein AN. The economic costs of illness: a replication and update. Health Care Financ Rev. 1985;7:61-80.

3. Hodgson TA, Cohen AJ. Medical care expenditures for selected circulatory diseases: opportunities for reducing national health expenditures. Med Care. 1999;37:9941012.

4. Cutler DM and Kadiyala S. The return to biomedical research: treatment and behavioral effects. In: Murphy KM and Topel RH (eds). Measuring the Gains from Medical Research. Chicago: University of Chicago Press; 2001: 110-162.

5. Harrison's Principles of Internal Medicine. New York: McGraw-Hill; 1962: 1346.

6. Joint National Committee. The fifth report of the Joint National Committee on detection, evaluation, and treatment of high blood pressure (JNC V). Arch Intern Med. 1993;153:154-183. As used by Wilson, et al., below.

7. Wilson PWF, D'Agostino RB, Levy D, Belanger AM, Silbershatz H, Kannel WB. Prediction of coronary heart disease using risk factor categories. Circulation. AHA; 1998.

8. Anderson KM, Odell PM, Wilson PWF, Kannel WB. Cardiovascular disease risk profiles. Am Heart J. 1990; 121: 293-8.

9. National Center for Health Statistics. United States Life Tables, 2001. National Vital Statistics Reports. 2001; Volume 52, Number 14. 
10. National Center for Health Statistics. Deaths: Final data for 2001. National Vital Statistics Reports. 2001; Volume 52, Number 3.

11. Standards Committee, American Society of Obesity Surgery; Obesity Surgery. Dec. 1997; 7:523.

12. Chobanian AV, Bakris GL, Black, HR, et al. Seventh Report of the Joint National Committee on Prevention, Detection, Evaluation, and Treatment of High Blood Pressure. Hypertension. 2003; 42: 1206-1252.

13. National Center for Health Statistics. Deaths: Injuries, 2001. National Vital Statistics Reports. 2001; Volume 52, Number 21.

14. Cutler DM. Your Money or Your Life. New York: Oxford University Press; 2004.

15. Hodgson T, Cai L. Medical care expenditures for hypertension, its complications and its comorbidities. Med Care. 2001; 39: 599-615.

16. Weinstein M. Spending health care dollars wisely: can cost-effectiveness analysis help? Sixteenth Annual Herbert Lourie Memorial Lecture on Health Policy. No. 30/2005, at p. 5. Available at: http://www-cpr.maxwell.syr.edu/pbriefs/pb30.pdf. Accessed April 4, 2005.

17. Hodgson TA and Cohen AJ. Medical care expenditures for selected circulatory diseases: opportunities for reducing national health expenditures. Med Care. 1999; 37: 994-1012.

18. Centers for Medicare and Medicaid Services. National health expenditure amounts, and average annual change, by type of expenditure; selected calendar years, 19902013. Available at: http://www.cms.hhs.gov/statistics/nhe/projections-2003/t2.asp. Accessed February 25, 2005. 
19. Taylor TN, Davis PH, Torner JC, Holmes J, Meyer JW, and Jacobson MF. Lifetime cost of stroke in the United States. Stroke. 1996; 27: 1459-1466.

20. Goff DC, Howard G, Russell G, and Labarthe D. Birth Cohort Evidence of Population Influences on Blood Pressure in the United States, 1887-1994. Ann Epidemiol. 2001; 11: 271-279. 


\section{Tables and Figures}

Table 1. Structural Model of Untreated Systolic and Diastolic Blood Pressure for Men and Women ages 30 to 79

\begin{tabular}{|c|c|c|c|c|c|c|c|c|c|c|c|}
\hline \multirow{4}{*}{ Variable } & \multicolumn{5}{|c|}{ Systolic Blood Pressure } & \multicolumn{6}{|c|}{ Diastolic Blood Pressure } \\
\hline & \multicolumn{2}{|c|}{ Men } & \multicolumn{3}{|c|}{\begin{tabular}{|c|} 
Women \\
\end{tabular}} & \multicolumn{3}{|c|}{ Men } & \multicolumn{3}{|c|}{ Women } \\
\hline & \multirow[b]{2}{*}{ Coefficient } & \multirow{2}{*}{$\begin{array}{c}\text { Standard } \\
\text { Error }\end{array}$} & \multirow[b]{2}{*}{ Coefficient } & \multicolumn{2}{|c|}{ Standard } & \multirow[b]{2}{*}{ Coefficient } & \multicolumn{2}{|c|}{ Standard } & \multirow{2}{*}{\multicolumn{2}{|c|}{ Coefficient }} & \multirow{2}{*}{$\begin{array}{c}\text { Standard } \\
\text { Error }\end{array}$} \\
\hline & & & & & Error & & & Error & & & \\
\hline Black & 7.605 & 1.327 & 8.114 & * & 1.341 & 5.662 & * & 0.790 & 5.631 & * & 0.741 \\
\hline Other & -5.246 & 3.043 & -13.337 & * & 3.683 & 0.190 & & 1.811 & -3.367 & $\star \star \star *$ & 2.036 \\
\hline Age 35-39 & 0.139 & 1.489 & 0.958 & & 1.536 & 1.330 & & 0.886 & 1.233 & & 0.849 \\
\hline Age $40-44$ & 2.371 & 1.470 & 6.577 & * & 1.589 & 3.348 & * & 0.875 & 3.940 & * & 0.879 \\
\hline Age $45-49$ & 4.641 & 1.503 & 10.912 & * & 1.587 & 4.599 & * & 0.894 & 5.223 & * & 0.877 \\
\hline Age 55-59 & 11.501 & 1.635 & 21.105 & * & 1.717 & 5.063 & * & 0.973 & 7.149 & * & 0.949 \\
\hline Age $60-64$ & 15.238 & 1.688 & 27.409 & * & 1.833 & 5.017 & * & 1.005 & 7.817 & * & 1.013 \\
\hline Age $65-69$ & 19.443 & 1.816 & 34.495 & * & 1.842 & 3.680 & * & 1.081 & 7.742 & * & 1.018 \\
\hline Age $70-74$ & 24.767 & 2.014 & 42.432 & * & 2.020 & 3.289 & * & 1.199 & 4.821 & * & 1.117 \\
\hline Age $75+$ & 29.205 & 2.344 & 36.163 & * & 2.495 & 2.715 & ** & 1.395 & 3.157 & ** & 1.379 \\
\hline BMI & 2.567 & 0.806 & 1.722 & * & 0.551 & 2.007 & * & 0.480 & 1.295 & * & 0.305 \\
\hline BMI 2 & -0.025 & 0.015 & -0.006 & & 0.010 & -0.021 & ** & 0.009 & -0.008 & & 0.005 \\
\hline Diabetes & 0.987 & 3.806 & 6.733 & ** & 2.902 & 1.125 & & 2.265 & -0.297 & & 1.604 \\
\hline
\end{tabular}

Note: * indicates significance at the $1 \%$ level; ${ }^{* *}$ at the $5 \%$ level; ${ }^{* *}$ at the $10 \%$ level.

Omitted category for race is white; for age, omitted category is 30-34. 
Table 2: Predicted Achieved and Potential Further Improvements in Life Expectancy and Deaths Avoided, 2001, and Hospital Discharges for MI and Stroke Avoided, 2002, Men and Women

\begin{tabular}{|c|c|c|c|c|c|c|c|c|c|c|c|c|}
\hline \multirow[b]{2}{*}{ Sex and age } & \multicolumn{4}{|c|}{ Deaths from Major Cardiovascular Disease, 2001} & \multicolumn{4}{|c|}{ Hospital Discharges for Stroke, 2002} & \multicolumn{4}{|c|}{ Hospital Discharges for Myocardial Infarction, 2002} \\
\hline & $\begin{array}{c}\text { 10-Year } \\
\text { Relative Risk of } \\
\text { CHD Event }{ }^{*} \\
\end{array}$ & Observed & $\begin{array}{c}\text { Avoided Due } \\
\text { to AHRT } \\
\text { Therapy ** } \\
\end{array}$ & $\begin{array}{l}\text { Improvement } \\
\text { Possible if } \\
\text { Guideline } \\
\text { Blood } \\
\text { Pressures } \\
\text { Achieved } \\
\end{array}$ & \begin{tabular}{|l|} 
\\
5-Year Relative \\
Risk of Stroke *
\end{tabular} & Observed & $\begin{array}{l}\text { Avoided Due } \\
\text { to AHRT } \\
\text { Therapy *t } \\
\end{array}$ & \begin{tabular}{|c|} 
Improvement \\
Possible if \\
Guideline \\
Blood \\
Pressures \\
Achieved \\
\end{tabular} & \begin{tabular}{|c|} 
\\
5-Year Relative \\
Risk of \\
Myocardial \\
Infarction \\
\end{tabular} & Observed & $\begin{array}{c}\text { Avoided Due } \\
\text { to AHRT } \\
\text { Therapy ** }\end{array}$ & \begin{tabular}{|c|} 
Improvement \\
Possible if \\
Guideline \\
Blood \\
Pressures \\
Achieved \\
\end{tabular} \\
\hline TOTAL & & 910,126 & $\begin{array}{r}86,098 \\
\end{array}$ & 89,150 & & 915,022 & \begin{tabular}{|r|}
571,930 \\
\end{tabular} & \begin{tabular}{|r|}
278,160 \\
\end{tabular} & & 794,080 & 260,701 & 142,696 \\
\hline MALE & & 420,330 & 49,884 & 49,951 & & 417,415 & 161,994 & 122,527 & & 461,245 & 86,866 & 67,312 \\
\hline 40 to 44 years & $\begin{array}{c}1.027 \\
1.017,1.037 \\
\end{array}$ & 7,508 & 937 & 845 & $\begin{array}{c}1.482 \\
1.400,1.565 \\
\end{array}$ & 8,991 & 4,336 & 621 & $\begin{array}{c}1.284 \\
1.207,1.361 \\
\end{array}$ & 26,079 & 7,395 & 1,110 \\
\hline 45 to 49 years & $\begin{array}{c}1.027 \\
1.017,1.037\end{array}$ & 12,418 & 1,270 & 1,145 & $\begin{array}{c}1.312 \\
1.235,1.388\end{array}$ & 19,011 & 5,923 & 2,148 & $\begin{array}{c}1.179 \\
1.126,1.231\end{array}$ & 27,741 & 4,954 & 1,793 \\
\hline 50 to 54 years & $\begin{array}{c}1.056 \\
1.038,1.073\end{array}$ & 18,442 & 3,261 & 2,324 & $\begin{array}{c}1.233 \\
1.171,1.295\end{array}$ & 23,094 & 5,388 & 5,101 & $\begin{array}{c}1.103 \\
1.070,1.137\end{array}$ & 45,416 & 4,697 & 6,171 \\
\hline 55 to 59 years & $\begin{array}{c}1.056 \\
1.038,1.073 \\
\end{array}$ & 22,489 & 3,689 & 2,629 & $\begin{array}{c}1.334 \\
1.255,1.414 \\
\end{array}$ & 32,509 & 10,870 & 6,929 & $\begin{array}{c}1.166 \\
1.116,1.217 \\
\end{array}$ & 55,019 & 9,142 & 6,453 \\
\hline 60 to 64 years & $\begin{array}{c}1.064 \\
1.051,1.077 \\
\end{array}$ & 27,831 & 5,067 & 4,266 & $\begin{array}{c}1.512 \\
1.434,1.589 \\
\end{array}$ & 45,942 & 23,517 & 10,925 & $\begin{array}{c}1.244 \\
1.204,1.285 \\
\end{array}$ & 49,159 & 12,003 & 6,407 \\
\hline 65 to 69 years & $\begin{array}{c}1.064 \\
1.051,1.077 \\
\end{array}$ & 36,221 & 6,506 & 5,478 & $\begin{array}{c}1.378 \\
1.316,1.440 \\
\end{array}$ & 48,040 & 18,161 & 15,124 & $\begin{array}{c}1.187 \\
1.155,1.218 \\
\end{array}$ & 56,299 & 10,508 & 8,880 \\
\hline 70 to 74 years & $\begin{array}{c}1.042 \\
1.032,1.053\end{array}$ & 51,535 & 5,855 & 6,681 & $\begin{array}{c}1.391 \\
1.318,1.464\end{array}$ & 66,281 & 25,923 & 22,573 & $\begin{array}{c}1.189 \\
1.151,1.228\end{array}$ & 53,954 & 10,218 & 9,771 \\
\hline 75 years and over & $\begin{array}{c}1.042 \\
1.032,1.053 \\
\end{array}$ & 243,886 & 23,299 & 26,584 & $\begin{array}{c}1.391 \\
1.318,1.464 \\
\end{array}$ & 173,547 & 67,875 & 59,105 & $\begin{array}{c}1.189 \\
1.151,1.228 \\
\end{array}$ & 147,578 & 27,949 & 26,727 \\
\hline Improvement in Life Expectancy & & & 0.5 & 0.5 & & & & & & & & \\
\hline FEMALE & & 489,796 & 36,214 & 39,199 & & 497,607 & 409,936 & 155,632 & & 332,835 & 173,835 & 75,384 \\
\hline \begin{tabular}{|l}
40 to 44 years \\
\end{tabular} & $\begin{array}{c}1.048 \\
1.035,1.061\end{array}$ & 3,610 & 979 & 213 & $\begin{array}{c}1.665 \\
1.565,1.765 \\
\end{array}$ & 7,795 & 5,184 & 402 & $\begin{array}{c}1.633 \\
1.412,1.855 \\
\end{array}$ & 7,638 & 4,838 & 344 \\
\hline 45 to 49 years & $\begin{array}{c}1.048 \\
1.035 \cdot 1.061\end{array}$ & 5,350 & 1,308 & 284 & $\begin{array}{c}1.670 \\
1.556 \cdot 1.785\end{array}$ & \begin{tabular}{ll|l}
16,598 \\
\end{tabular} & 11,128 & 1,451 & $\begin{array}{c}1.601 \\
1.425,1.778\end{array}$ & 11,502 & 6,918 & 910 \\
\hline 50 to 54 years & $\begin{array}{c}1.042 \\
1.026,1.057\end{array}$ & 8,240 & 1,514 & 842 & $\begin{array}{c}1.422 \\
1.337,1.506\end{array}$ & 28,323 & 11,943 & 5,514 & $\begin{array}{c}1.323 \\
1.231,1.415\end{array}$ & 13,905 & 4,487 & 2,061 \\
\hline 55 to 59 years & $\begin{array}{c}1.042 \\
1.026,1.057\end{array}$ & $\begin{array}{ll}10,846 \\
\end{array}$ & 1,837 & 1,022 & $\begin{array}{c}1.635 \\
1.523,1.746\end{array}$ & 26,132 & $\begin{array}{ll}16,582 \\
\end{array}$ & 5,155 & $\begin{array}{c}1.446 \\
1.323,1.569\end{array}$ & 29,537 & 13,165 & 4,139 \\
\hline 60 to 64 years & $\begin{array}{c}1.072 \\
1.057,1.088 \\
\end{array}$ & 15,058 & 4,009 & 2,387 & $\begin{array}{c}1.660 \\
1.545,1.776\end{array}$ & 37,766 & 24,938 & 9,855 & $\begin{array}{c}1.404 \\
1.312,1.496\end{array}$ & 26,852 & 10,844 & 4,930 \\
\hline 65 to 69 years & $\begin{array}{c}1.072 \\
1.057,1.088 \\
\end{array}$ & 22,845 & 5,479 & 3,262 & $\begin{array}{c}1.823 \\
1.695,1.952 \\
\end{array}$ & 42,976 & 35,389 & 12,373 & $\begin{array}{c}1.526 \\
1.407,1.645 \\
\end{array}$ & 36,247 & 19,081 & 7,219 \\
\hline 70 to 74 years & $\begin{array}{c}1.023 \\
1.016,1.030 \\
\end{array}$ & 37,808 & 2,607 & 3,856 & $\begin{array}{c}1.902 \\
1.771,2.032 \\
\end{array}$ & 64,382 & 58,050 & 23,024 & $\begin{array}{c}1.553 \\
1.448,1.658 \\
\end{array}$ & 34,794 & 19,232 & 9,369 \\
\hline 75 years and over & $\begin{array}{c}1.023 \\
1.016,1.030 \\
\end{array}$ & 386,039 & 18,482 & 27,332 & $\begin{array}{c}1.902 \\
1.771,2.032 \\
\end{array}$ & 273,635 & 246,722 & 97,858 & $\begin{array}{c}1.553 \\
1.448,1.658 \\
\end{array}$ & 172,360 & 95,270 & 46,411 \\
\hline Improvement in Life Expectancy & & & 0.4 & 0.3 & & & & & & & & \\
\hline
\end{tabular}

*95\% confidence interval.

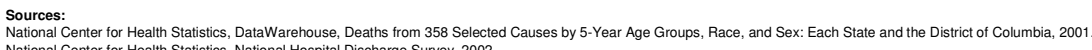
Wilson PWF, D'Agostino RB, Levy D, Belanger AM, Silbershatz H, Kannel WB. Prediction of coronary heart disease using risk factor categories. Circulation. AHA; 1998.
Anderson KM, Odell PM, Wilson PWF, Kannel WB. Cardiovascular disease risk profiles. Am Heart J. 1990; 121: 293-8. 
Figure 1: Predicted and Observed Blood Pressure, Men, 1999-2000

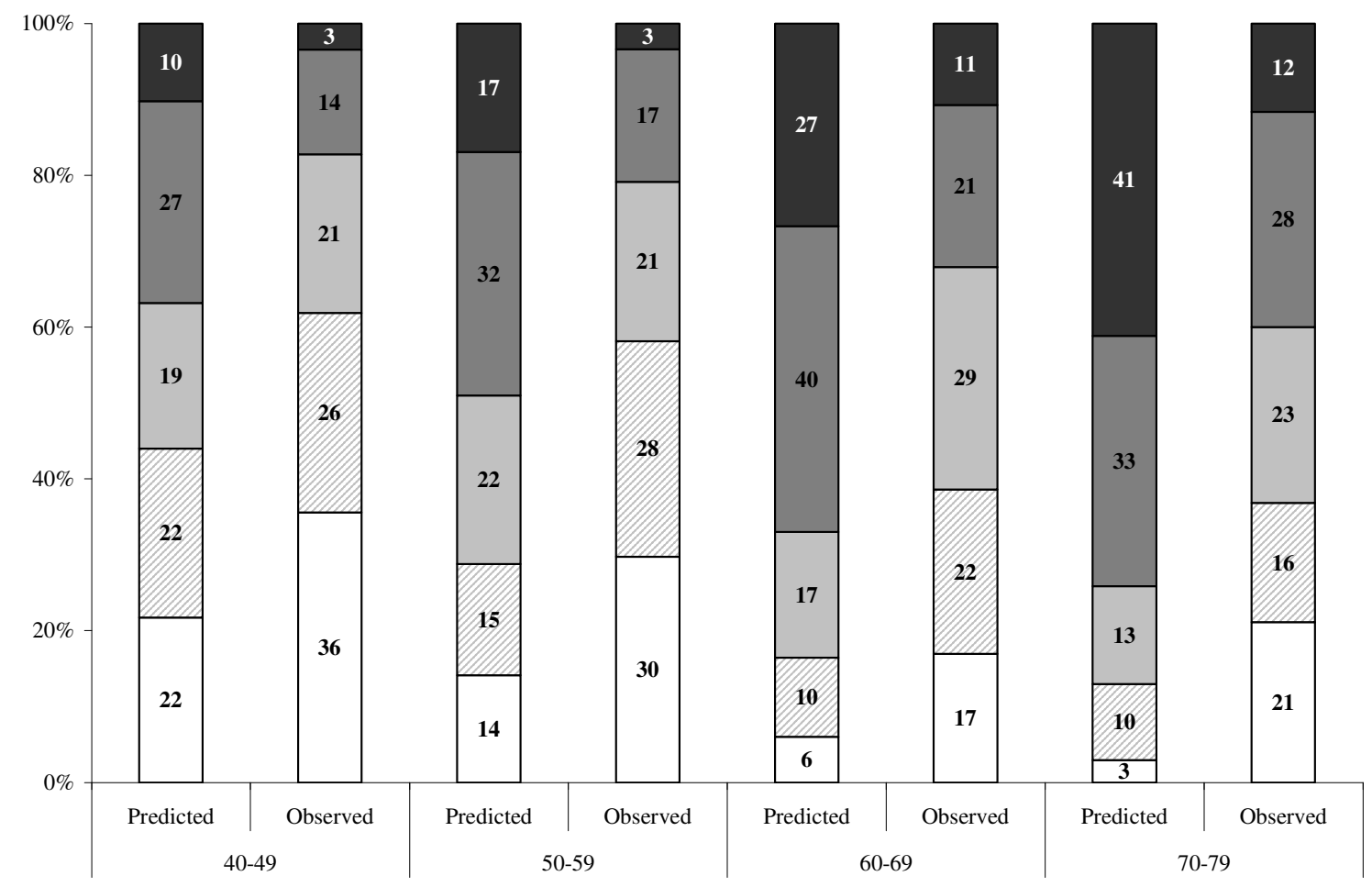

$\square$ Optimal $\square$ Normal $\square$ High Normal $\square$ Stage I Hypertension $\square$ Stage II Hypertension

Predicted and Observed Blood Pressure, Women, 1999-2000

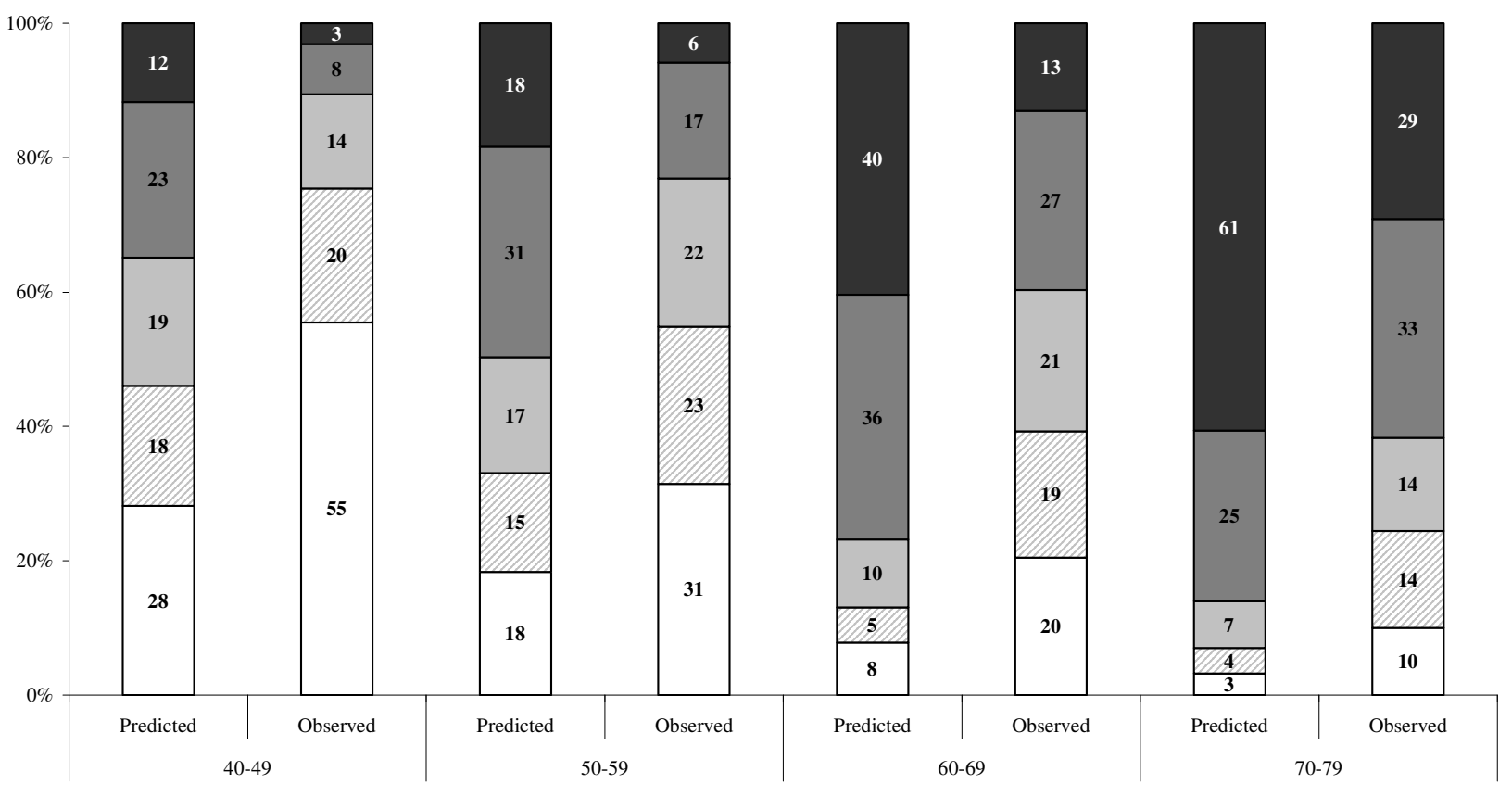

口Optimal $\square$ Normal $\square$ High Normal $\square$ Stage I Hypertension $\square$ Stage II Hypertension

Optimal: SBP<120, DBP< 80; Normal: SBP 120-129, DBP 80-84; High Normal: SBP 130-139, DBP 85-89; Stage I: SBP 140-159, DBP 90-99; Stage II Hypertension: SBP $>=160$, DBP $>=100$ 
Figure 2: Predicted and Observed Deaths, 2001, and Hospital Discharges for Stroke and MI, 2002, Men and Women

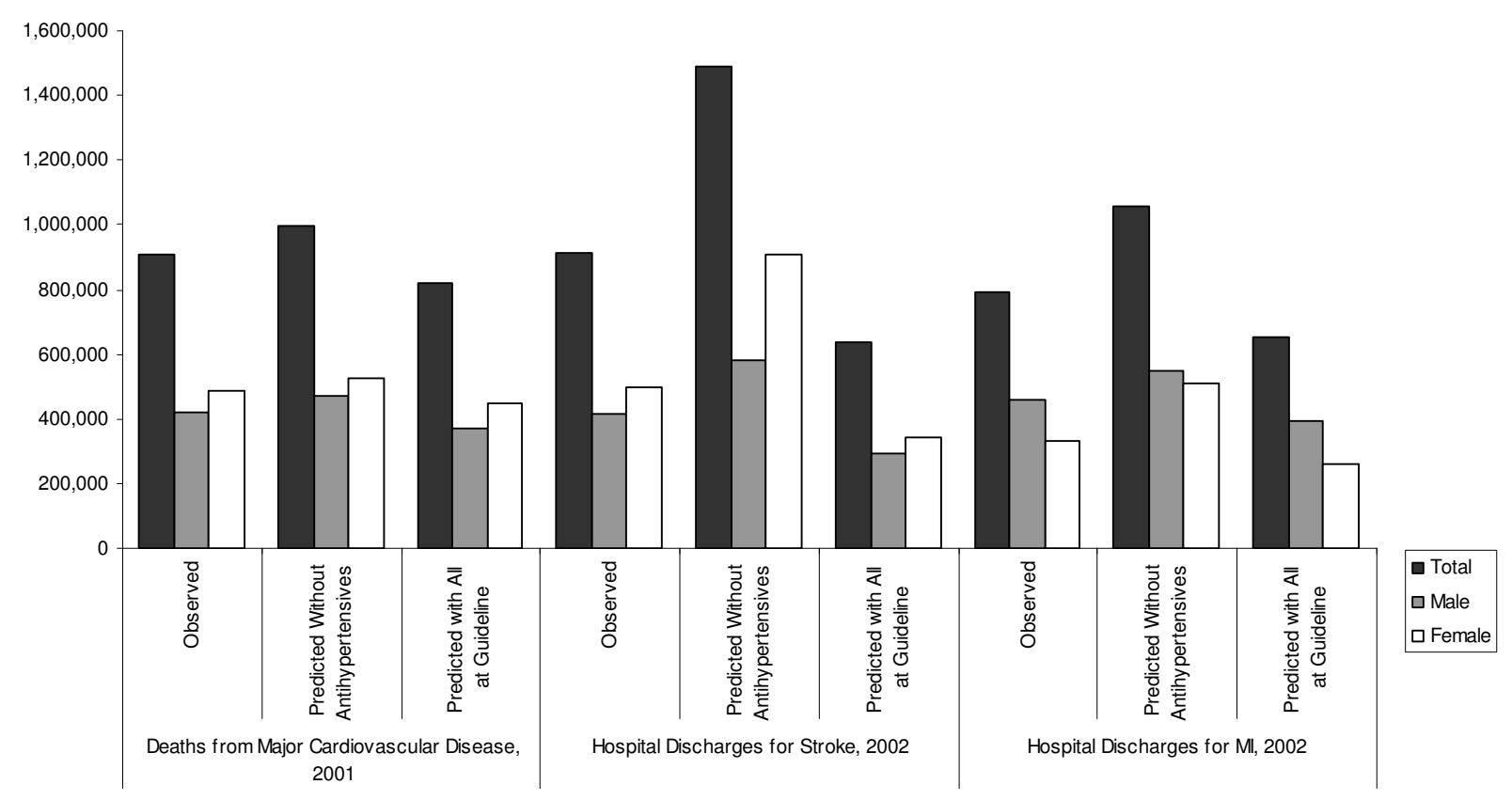

